\title{
A evolução do rádio e 0 impacto na/da audiência ${ }^{1}$
}

////////////////// Marko Ala-Fossi ${ }^{2}$

1. Este artigo é baseado numa apresentação feita durante a conferência Radio e-volution, realizada em Braga, Portugal, em 16 de setembro de 2011. O autor agradece a Montse Bonet (Universidade Autônoma de Barcelona) e a Ulrich Heinze (Universidade de East Anglia) pela cooperação acadêmica com este trabalho na recuperação de dados sobre a audiência internacionalmente.

2. Doutor em ciências sociais e professor de rádio e professor adjunto de jornalismo e comunicação de massa na Universidade de Tampere, Finlândia. É também membro da equipe pan-europeia de pesquisa em rádio digital (Drace). E-mail: marko.ala-fossi@uta.fi 


\section{Resumo}

A evolução do rádio depende em grande parte não apenas dos contextos culturais de um país mas também do desenvolvimento social, político e econômico geral das sociedades. Somado a isso, ela acontece no intercâmbio com todas as outras formas de mídia, e esse é o motivo pelo qual não há uma evolução do rádio que seja ou isolada ou universal. A importância crescente da internet e o aumento da popularidade da banda larga móvel, em conjunto com mudanças econômicas e demográficas em curso numa escala global, continuam a ter efeito polarizador: possivelmente o rádio já teve seu auge no mundo ocidental, enquanto na Ásia e África ele ainda tem um potencial enorme de crescimento.

\section{Palavras-chave}

Rádio, transmissão radiofônica, evolução, audiência, mídia.

Abstract The evolution of radio is highly dependent not only on the national cultural contexts but also on the overall social, political and economic development of the societies. In addition, it happens in interplay with all the other forms of media and this is why there is no universal or separate evolution of radio. The growing importance of the internet and increasing popularity of mobile broadband together with the ongoing economic and demographic changes on a global scale continue to have a polarized effect: in the Western world, broadcast radio may have already had its alltime high, while in Asia and Africa, broadcast radio has still a huge potential for growth.

Radio, broadcasting, evolution, audience, media. 


\section{Introdução}

A proposta deste estudo é examinar o relacionamento entre aspectos da mídia sonora que estão em transformação e seu público, abordados em estudo anterior (ALA-FOSSI et al, 2008) realizado pelo grupo de pesquisa Drace tratando do futuro do rádio. Naquele momento, definiu-se uma matriz de quatro cenários principais, considerando a tecnologia de entrega e o consumo de conteúdo como as principais variáveis. O presente artigo pretende destacar algumas das perspectivas e ideias mais recentes sobre a dinâmica que se estabelece entre a evolução do rádio e o relacionamento com seu público a partir dos quatro temas principais elencados abaixo:

Em primeiro lugar, o que já sabemos sobre a transformação do rádio e da mídia sonora? O rádio é uma mídia de massa que tem 90 anos. Há padrões que se repetem e que são facilmente identificáveis no desenvolvimento do rádio e, assim, podem aparecer novamente - o quanto seremos capazes de entender e interpretar a informação sobre tais progressos? Em segundo lugar, embora não haja como prever o comportamento exato do público do rádio e da mídia sonora no futuro, é possível ter uma ideia de qual será o tamanho potencial e de quais serão as preferências desse público a partir dos dados recuperados hoje? Finalmente, qual é a verdadeira relação entre a evolução da mídia e seu público: a evolução do rádio como meio simplesmente conforma a audiência? Ou até que ponto devemos assumir que, na verdade, é o público que por fim define o meio e sua evolução? 


\section{O que já sabemos sobre a transformação do rádio?}

O relato de como, nos anos 50, o rádio perdeu o lugar de objeto central na sala de estar assim que uma nova forma de transmissão, a televisão, foi introduzida é parte essencial da história canonizada da mídia massiva no mundo ocidental. Todo pesquisador na área de mídia sabe a história de como a velha rede radiofônica perdeu prevalência nos Estados Unidos, de como as estações de rádio independentes, pequenas e desesperadas, começaram a tocar mais música - também para um público mais jovem, equipado com receptores móveis e portáteis - , e de como as estações de rádio passaram a seguir certas fórmulas previsíveis e a introduzir estilos de música novos e estimulantes. Tudo isso, somado ao concomitante desenvolvimento das pesquisas sobre audiência e sobre a indústria musical, abriu o caminho para o nascimento do formato do rádio musical.

Essa mesma história da reinvenção ou da transformação do rádio é amplamente repetida em diversos livros de referência escritos em inglês, e agora também aparece no novo capítulo de John Carey sobre a evolução do rádio. Na verdade, Carey leva a ideia um pouco além, já que sugere que o rádio reinventou-se não uma vez só, mas pelo menos duas vezes - e está tentando fazê-lo de novo hoje - , como se houvesse um ciclo de desenvolvimento contínuo do rádio, com fases que se repetem:

\footnotetext{
Sob muitos aspectos, a era moderna dos serviços radiofônicos é uma tentativa de reinventar o rádio. Isso já aconteceu algumas vezes antes. Nos anos 50, sob a ameaça da competição com a televisão, o rádio se reinventou colocando-se como serviço para ambiências móveis (carros e rádios portáteis) e, em vez de diferentes modelos de conteúdo em cada estação, passou a ter uma programação com formato único (CAREY, 2010, p. 76).
}

Sim, a ideia parece bem razoável - se continuarmos falando dos Estados Unidos da América. Mas, se formos olhar para o desenvolvimento do rádio no Japão do final dos anos 50, a história da reinvenção definitivamente não se encaixará no quadro geral. 
No Japão, se a reinvenção nunca aconteceu — ou se seu efeito foi totalmente oposto àquele obtido nos Estados Unidos - , assim que a televisão foi introduzida, ela substituiu amplamente o rádio, cuja popularidade decaiu num curto período de tempo. O número de receptores de rádio contratados no Japão teve seu auge em 1958, cinco anos depois da introdução da televisão - e depois disso começou a decair de forma tão rápida que a taxa para ter uma licença radiofônica pôde ser extinta em 1968 (NHK 1977, p. 246247) - , enquanto na Finlândia, por exemplo, o número de licenças radiofônicas válidas continuava a crescer, independentemente de haver a televisão, até o momento da extinção da licença relacionada aos receptores de rádio, em 1977 (ALA-FOSSI, 2012b, p. 36).

Talvez seja correto dizer que, no Japão, o rádio morreu no final dos anos 50 por causa da televisão e não renasceu mais desde então. Nos anos 60, o tempo médio que se gastava ouvindo rádio no Japão era de uma hora e 34 minutos; cinco anos depois, esse índice havia caído para apenas 27 minutos (NHK, 2002, p. 171). Se não considerarmos um rápido radio boom nos anos 70, o tempo médio gasto em ouvir rádio acabou permanecendo bem baixo e, quando comparado internacionalmente, o Japão se diferencia dos países industrializados do Ocidente. 60\% dos japoneses adultos nunca ouvem rádio - enquanto na maior parte dos países europeus e também nos nórdicos, além daqueles da América do Norte, a situação é exatamente oposta, e o alcance semanal do rádio entre os adultos supera 70\%. Um dos motivos para o baixo índice de ouvintes no Japão é a contínua popularidade dos programas televisivos matinais: o rádio não goza de nenhum pico de audiência durante o dia, nem mesmo durante o período do café da manhã. Assim como afirma Heinze (2011), o rádio no Japão é “o meio de comunicação de massa minoritário” (YOSHIDA; NAKANO, 2007, p. 130; OFCOM, 2008, p. 246; HEINZE, 2011).

Dessa forma, a evolução do rádio não acontece do nada, mas num intercâmbio com o desenvolvimento e introdução de novas mídias. Uma abordagem intermidiática se faz necessária, já que não existe uma história própria - ou um futuro - da mídia radiofônica separadamente. Somado a isso, é absolutamente 
essencial que sejam realizadas pesquisas e análises sobre o rádio e sobre o desenvolvimento de seu público em nível nacional. De qualquer forma, nossas culturas e nossas sociedades são diferentes, e a evolução do rádio ou seu impacto na audiência - bem como as mudanças no comportamento da audiência - não são similares ou simultâneos em todos os lugares. Por isso, não é prudente fazer amplas generalizações sobre o desenvolvimento do rádio com base em qualquer dos mercados particulares, independentemente de quão grande e importante ele seja. Uma abordagem comparativa e uma perspectiva global são necessárias para um melhor entendimento da questão.

O Reino Unido tem um dos mercados de rádio digital mais bem sucedidos da Europa, onde o setor envolveu-se totalmente no padrão DAB (digital audio broadcasting). A RAB (Radio Advertising Bureau), seção de propaganda para o rádio, tem vendido essa mudança como uma evolução dinâmica do rádio dentro do mercado do país. Em suas publicações, vem tentando ilustrar como o rádio poderia ser neste momento uma quantidade de aparatos digitais diferentes em diferentes plataformas, tudo ao mesmo tempo, sem ser apenas uma só caixa com som (RAB, 2009a). Nos anos 50, novos transistores portáteis possibilitaram ouvir rádio em lugares diferentes, em tempos diferentes. A RAB agora está tentando nos apresentar essa mesma ideia como sendo o impacto da recepção do rádio em multiplataformas nos modos contemporâneos de ouvir. De acordo com a argumentação oficial, um maior número de plataformas digitais seria equivalente a mais pessoas ouvindo, o que é necessário, é claro, para conseguir mais anunciantes e para gerar mais recursos. Contudo, eles parecem ignorar os cursos crescentes das simulcasting (simultaneous broadcast/transmissão simultânea) em multiplataformas - e o fato de que adicionar mais plataformas de maneira nenhuma implica obrigatoriamente aumentar o número total de ouvintes.

A atividade de prover serviços digitais de rádio tem sido apresentada como uma alternativa para conquistar o público jovem - a estratégia seria a de que, se houver serviços digitais adicionais e até mesmo imagens no rádio, esse público vai vir e também vai 
Figural: Índice de audição de rádio (o alcance e a média diária de ouvintes) e o número de casas com internet banda larga na Finlândia - 1991-2010. Fontes: Finnpanel e Statistics Finland ficar por mais tempo (RAB, 2009b). Quando observamos o perfil dos ouvintes de rádio no Reino Unido, pode parecer a princípio que essa estratégia de multiplataformas digitais pode funcionar bem. A atividade de ouvir rádio atingiu novos recordes em maio de 2011 - o índice semanal ficou acima de $91 \%$ da população do Reino Unido com 15 anos de idade (BBC, 2011 a; BBC, 2011b). No entanto, esse sucesso estrondoso do rádio entre o público jovem acabou tornandose um grande problema para a indústria radiofônica. Muitas pessoas ainda estão ouvindo demais um tipo errado de rádio: as gerações mais antigas estão muito ligadas aos seus aparelhos analógicos antigos e estão menos propensas a ouvir rádio através de uma plataforma digital, enquanto os mais jovens importam-se cada vez menos com qualquer tipo de rádio e estão mais inclinados a não ouvir nada nele (OFCOM, 2011, p. 180-182).

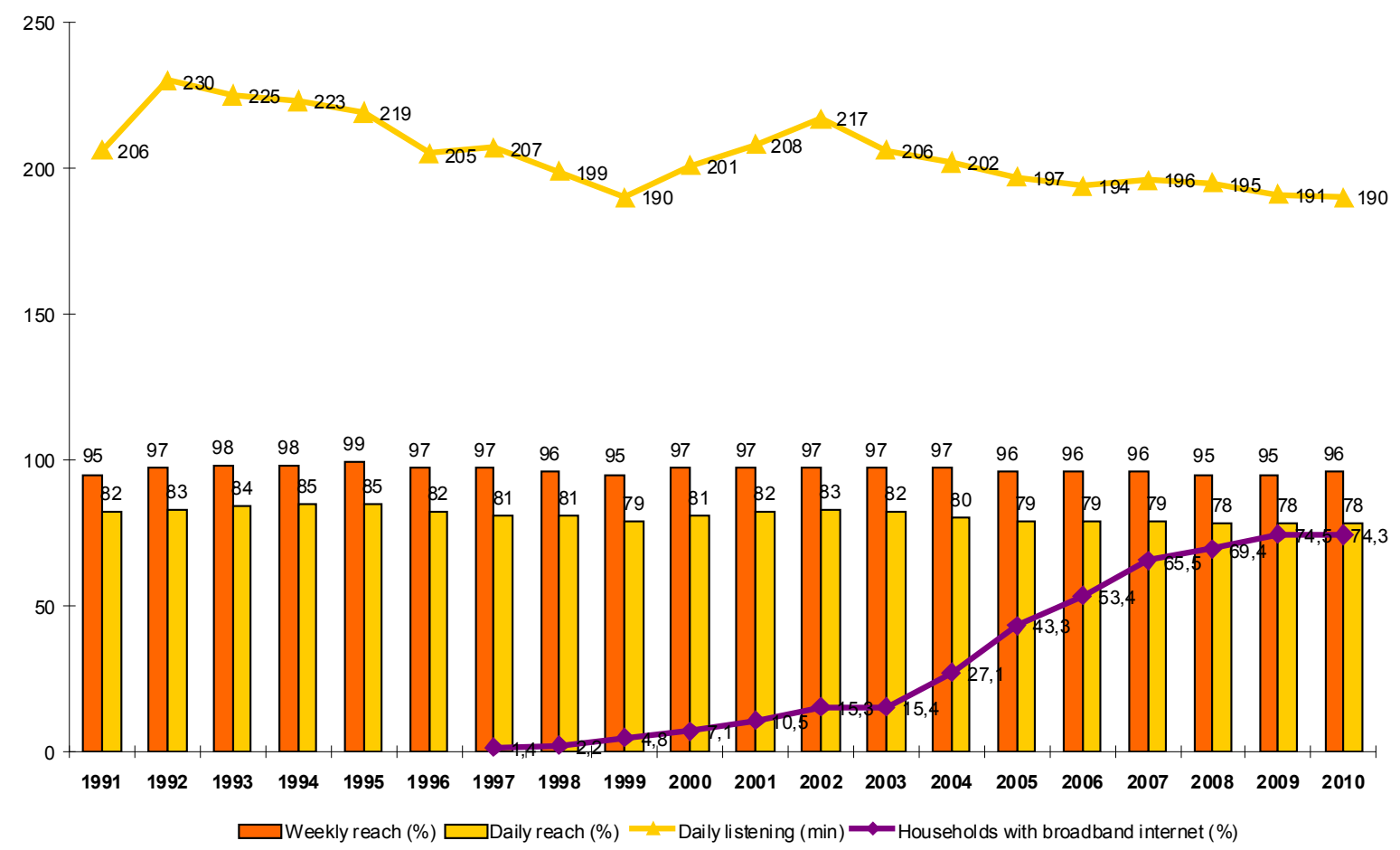


Embora haja altos índices de número de ouvintes também na Finlândia, o mercado radiofônico desse país é completamente diferente daquele do Reino Unido. A Finlândia assumiu a falência do rádio com a introdução do rádio digital — isso não uma vez só, mas duas. A emissora finlandesa pública de rádio, YLE, decidiu, no ano de 2005, encerrar o serviço DAB depois de sete solitários anos de serviços regulares praticamente sem público ouvinte - e, mais recentemente, em 2012, os serviços de rádio comerciais em padrão DVB-H também fecharam. Atualmente, a indústria radiofônica finlandesa tem intenções de permanecer com o FM analógico pelo menos até 2019, quando termina a licença vigente (ALA-FOSSI, 2012a). E, se observarmos o desenvolvimento dos índices de audição de rádio na Finlândia nos últimos 20 anos, a rádio FM analógica parece ter sido uma mídia bem estável (Figura 1), com um alcance impressionantemente alto. Independentemente de todas as outras opções de mídia disponíveis, mais de $95 \%$ da população finlandesa acima de nove anos de idade ouve rádio pelo menos uma vez por semana.

Contudo, se observarmos mais de perto os métodos de pesquisa utilizados na Finlândia, vamos descobrir que toda a audição de rádio hoje nas emissoras radiofônicas finlandesas, em qualquer plataforma, é computada como número total de ouvintes, em vez de só a audição registrada no FM. Teoricamente poderíamos fechar o FM finlandês sem causar nenhum buraco no número de ouvintes - garantindo que todos pudessem continuar a ouvir rádio através de alguma outra plataforma (ALA-FOSSI; HAARA, 2010, p. 21). O alcance do rádio na Finlândia parece ter se mantido quase imutável nas últimas duas décadas; ao mesmo tempo, é muito improvável que ele pudesse de alguma forma conseguir aumentar: hoje ele já é mais alto do que nos países da África subsaariana, onde o rádio é ainda a forma dominante de mídia massiva (AMDI, 2006; MYERS, 2008). Ao mesmo tempo, é bem provável que as mudanças nos índices diários e também no tempo que se gasta ouvindo rádio podem ter relação com o crescimento do uso de telefones móveis desde o início da década de 90 e com o crescente uso da internet banda larga no ambiente doméstico ocorrido nos últimos dez anos. 
Parece que tanto o caso do Reino Unido quanto o finlandês nos contam mais ou menos a mesma história: a indústria radiofônica comercial e as empresas de pesquisa de audiência tendem a não contribuir ativamente para nosso entendimento sobre as mudanças no comportamento do público resultantes da evolução do rádio e de outros meios, caso isso ameace seus próprios interesses comerciais. As entidades que produzem e interpretam dados sobre o rádio e seu público são, em muitos casos, também parte interessada, e elas preferem manter o status quo e proteger seus próprios interesses do que refletir todas as mudanças no comportamento da audiência e no ambiente midiático. Esse é o motivo pelo qual a pesquisa acadêmica independente e a co-operação internacional também são necessárias para que se atinja uma compreensão mais objetiva.

\section{O que já sabemos sobre como será o público do rádio no futuro?}

Em 2010, o departamento de pesquisa da Rádio Sueca (SR) começou a preparar um relatório sobre o futuro de rádio e assim pediu para que o autor deste artigo fizesse uma previsão de como progrediria o rádio na Suécia nos próximos 15 anos. Essa foi a primeira vez que usei o gráfico da Figura 2. Há dados de longo prazo disponíveis publicamente que tratam do alcance diário do rádio tanto na Finlândia quanto na Suécia (na base de dados Nordicom acessível na web). Baseado nesses dados, elaborei o gráfico do longo desenvolvimento dos últimos 20 anos e acrescentei traços de tendência lineares, que foram estendidos para 15 anos no futuro. Esse tipo de análise numérica é um método chamado extrapolação linear e ilustra a progressão futura, contando que as tendências do passado e do presente continuem similares. Parece que o alcance diário do rádio na Finlândia e na Suécia desenvolve-se de forma parecida: há sempre um decréscimo leve, mas contínuo.

Além de pedir minha contribuição, a rádio sueca também pediu que Magnus Anshelm, presidente do Instituto Sueco de Estatística em Propaganda e Mídia (Swedish Institute of Advertising and Media Statistics) e também Christer Jungeryd, presidente da Academia de Rádio (Radio Academy), fizessem uma análise. Somado a disso, a filial local da TNS, empresa no ramo de pesquisa de mercado, 
produziu um prognóstico especial para o relatório e, por fim, Jacob Bjur, um pesquisador sueco - que naquele momento estava trabalhando para a rádio sueca como pesquisador visitante também fez uma análise para a base de dados Nordicom do perfil do ouvinte do rádio nos países nórdicos. A pesquisa sobre o futuro da rádio sueca foi publicada finalmente em novembro de 2010, mas apenas na Suécia (SR, 2010a). Os três pontos principais do capítulo 7, que trata do futuro do consumo de mídia e da atividade de ouvir rádio, apresentam-se como segue:

Se a audição de rádio for extrapolada linearmente, baseando-se em seu desenvolvimento histórico, o alcance diário da rádio FM será reduzido em pelo menos 10 pontos percentuais em 10 anos. $\mathrm{O}$ alcance semanal decai mais vagarosamente, o que pode ser interpretado a partir do fato de que o rádio ainda é uma companhia para muitos, embora sem a mesma regularidade. E não com a mesma duração - o tempo de audição decresce mais, pelo menos 20 pontos percentuais a cada década. [...]

Um dos fatores que a equipe ressalta, juntamente com a extrapolação, é que as gerações mais jovens estão ouvindo cada vez menos rádio. Essa tendência fica clara com a geração de 80 e é acentuada com aqueles nascidos na década de 90 e provavelmente será intensificada ainda mais com aqueles nascidos nos anos 2000. Essa atividade [ouvir rádio] pode ser ainda mais diluída pelo fato de que os filhos daqueles nascidos nos anos 80 e 90 não estão mais crescendo com um rádio na casa.

O rádio comercial baseado em programação musical já foi forte entre o grupo dos mais jovens, mas recentemente ele decresceu significativamente, conforme os serviços de música online atraíram o público. Os avaliadores observam ainda que, por exemplo, o futuro da rádio digital e as mudanças na estrutura do canal podem ter impacto na audição de rádio. Como conclusão, as análises mostram que a atividade de ouvir rádio pode decair numericamente um pouco mais do que a extrapolação linear indica. Mas até o ano de 2020 ela pode ainda atingir as marcas previstas relativamente bem - o efeito geracional mais amplo acontecerá depois disso (SR, 2010a, p. 33). 


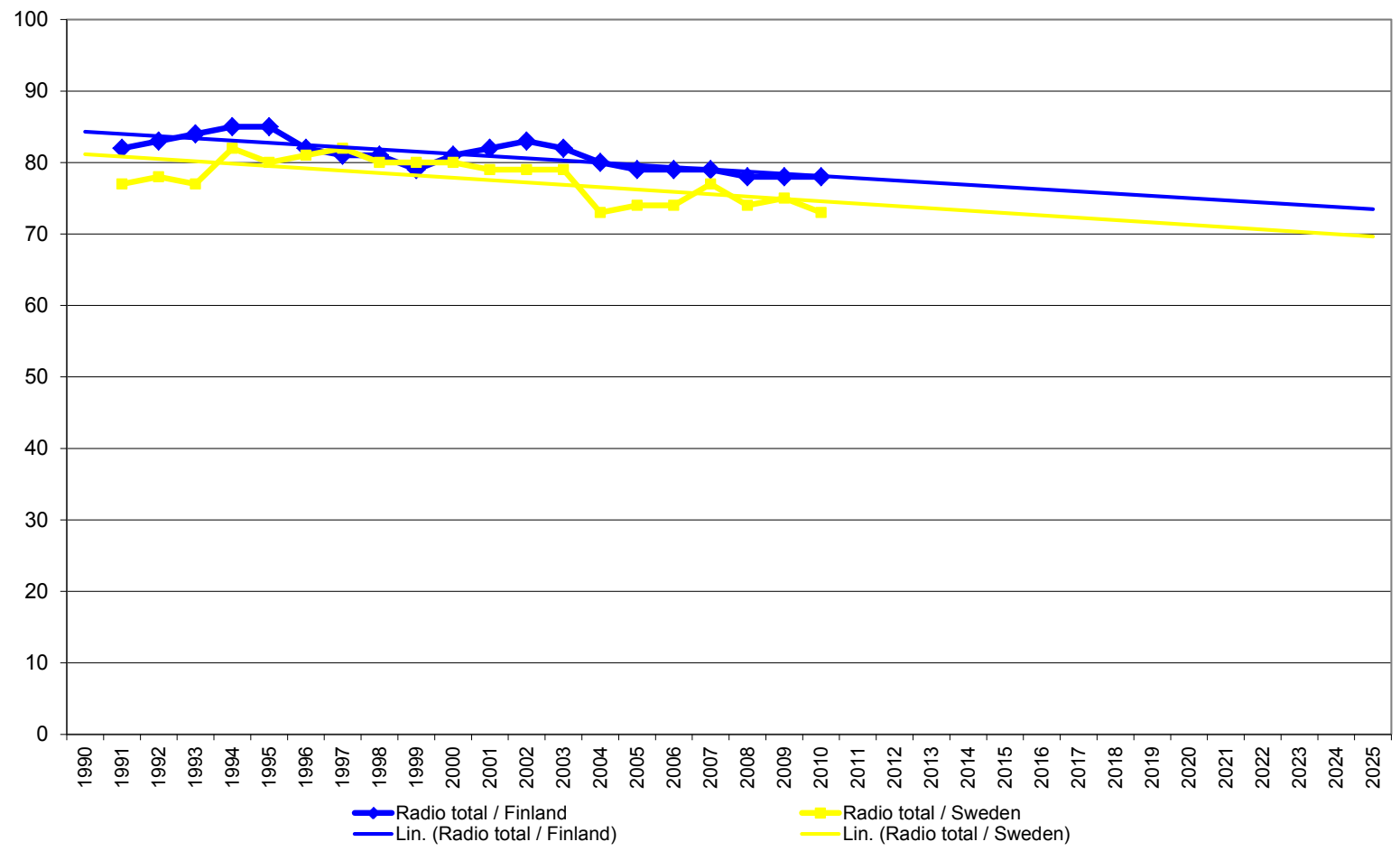

Figura 2: Alcance diário do rádio entre 1991-2010 na Finlândia e na Suécia (com linhas de tendência extrapoladas até 2025) Fontes: Nordicom e Finnpanel
Assim, é provável que, na Suécia, e também na Finlândia, o alcance diário do rádio seja reduzido em pelo menos dez pontos percentuais nos próximos dez anos - e o tempo de audição sofra redução ainda mais rapidamente, cerca de 20 pontos percentuais em dez anos. Indivíduos que completarão 40, 30, 20 anos nos próximos dez anos já hoje ouvem menos rádio em comparação com as gerações mais velhas nas mesmas faixas etárias - e seus filhos não serão habituados ao rádio em casa tão cedo. Um dos motivos para que o rádio não seja mais tão importante para os mais jovens são os serviços de música online. As mudanças na forma de oferecimento e na entrega da transmissão de rádio devem também ter impacto, mas é muito provável que a redução gradual na atividade de ouvir rádio continue ao menos pelos próximos dez anos - depois disso, a redução pode ser ainda mais acelerada.

Com o objetivo de descobrir se a situação é a mesma apenas nos países nórdicos ou vale para a Europa inteira, decidi comparar esses dois casos com o de um país do sul do continente, que tem também uma tradição de rádio diferente. Foi assim que analisei, 
de maneira muito semelhante àquela com que estudei Finlândia e Suécia, dados sobre a audiência de rádio espanhola, contemplando um largo período reunido pelo Estudio General de Medios. Para minha surpresa inicial, descobri que o alcance diário do rádio na Espanha estava crescendo, ao invés de decrescendo, nas últimas duas décadas - e ainda que a tendência para a extrapolação futura aparentemente se mostrava contraditória com as previsões feitas para Finlândia e Suécia (ver Figura 3).

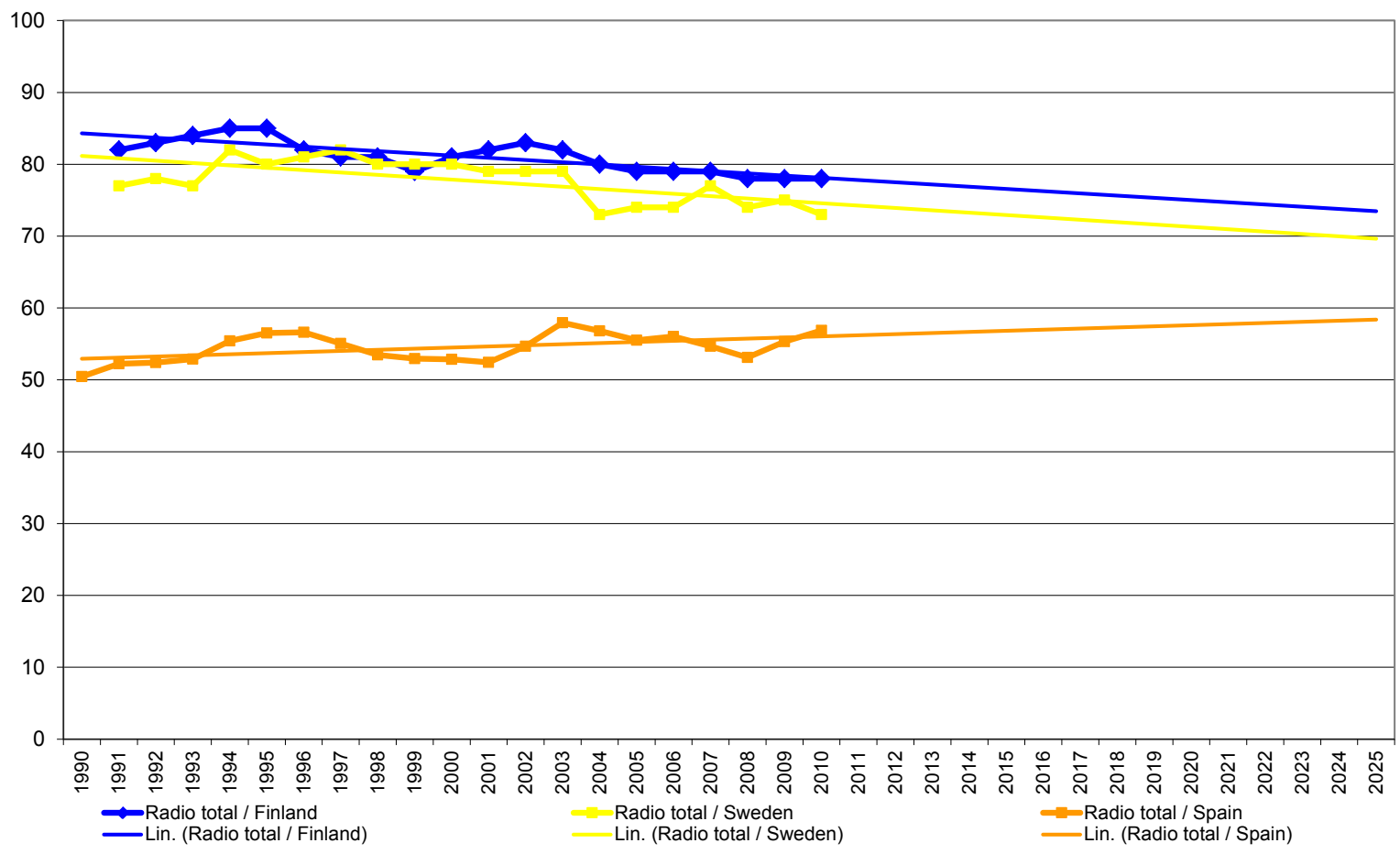

Figura 3: Alcance diário do rádio entre 1991-2010 na Finlândia, na Suécia e na Espanha (com linhas de tendência extrapoladas até 2015).

Fontes: Finnpanel, Nordicom e Estudio General de Medios
É um grande desafio estabelecer comparações em longo prazo sobre o desenvolvimento da audiência entre países diferentes. Não há padrões universais para a pesquisa de audiência, e em cada país os padrões geralmente sofreram alterações com o passar dos anos. Além disso, a categorização de dados pode ser bem incompatível. Mas, numa análise em maior detalhe, foi possível encontrar um denominador comum entre tendências na Finlândia, Suécia e Espanha: o alcance do formato musical no FM cresceu nos três países nas últimas duas décadas. No norte, emissoras de rádio privadas comerciais baseadas em programação musical haviam crescido, 
e os antigos e fortes serviços públicos de rádio - ambos apenas em FM - estavam em acentuado declínio, resultando numa redução generalizada do alcance diário do rádio. Da mesma forma, a Espanha tinha uma tradição maior de rádio particular e, apesar do declínio gradual do velho estilo, das emissoras particulares convencionais, assim como do rádio AM, o crescimento do formato do rádio musical para o FM resultou numa tendência generalizada de aumento do alcance diário do rádio. Mas atualmente é provável que o ápice do formato musical para o rádio já tenha passado em toda a Europa e também na Espanha.

\section{O que já sabemos sobre o futuro das preferências do público?}

Todos os relatórios recentes gerados dos dois lados do Atlântico sobre os jovens, o rádio e as novas mídias apresentam mais ou menos a mesma história. O consumo de rádio está sofrendo um declínio lento, mas constante, não apenas entre os jovens mas também em todo tipo de público. A transmissão radiofônica não é a segunda plataforma mais importante em que se ouve rádio: nesse lugar está a internet, depois da FM analógica, mesmo para quem transmite ao público europeu (EBU, 2011). Na última década, o rádio perdeu seu apelo para o público jovem não só como uma atividade matinal mas mesmo para o público em geral. No ano de 2000, um total de 74\% de jovens americanos entre 12 e 24 anos ouviam rádio regularmente pela manhã, mas, em 2010, apenas $41 \%$ deles ligavam o rádio durante o café da manhã. E a proporção no tempo total diário gasto ouvindo rádio era $15 \%$ aproximadamente a metade do que costumava ser dez anos antes (EDISON RESEARCH, 2010).

Quando falamos então da nova música, o público jovem tende a acessar a internet mais do que o rádio: serviços de música online como o Pandora, nos Estados Unidos, e o Spotufy, na Suécia, são altamente populares entre os indivíduos com menos de 35 anos de idade e mais populares ainda do que qualquer tipo de rádio. Mas aqueles que nasceram em meados dos anos 70 - e tinham 15 anos 
há 20 anos e agora estão com seus 30 anos avançados - ainda preferem acompanhar a transmissão de rádio a utilizar serviços de música baseados na internet (EDISON RESEARCH, 2011; EBU, 2011). Com base nesses relatórios, a idade de 35 anos parece ser um tipo de divisor de águas entre os radioheads e os nativos digitais ao menos na Suécia e nos Estados Unidos.

Concluindo, parece haver três tendências principais na atual evolução do rádio e do desenvolvimento de sua audiência no mundo ocidental. Em primeiro lugar, ouvir rádio está em muito lento, mas constante declínio generalizado, considerando-se uma perspectiva de longo prazo. Há muitas razões para explicar essa progressão, mas de maneira geral é provável que o tempo gasto com o rádio decresça ainda mais conforme aumentem o fornecimento e a variedade das opções de serviços radiofônicos ou dos substitutos deles. Em segundo lugar, apesar dos repetidos esforços em diversos países, a transmissão de rádio pela internet não teve um verdadeiro despontar, ao mesmo tempo que a internet já se fixou como a segunda plataforma mais importante de fornecimento de conteúdo radiofônico depois da FM. Em terceiro lugar, as gerações mais jovens, nascidas após a metade dos anos 70, estão optando cada vez mais pelos serviços de música personalizados online, em vez de estações de música no ar. Todo esse conjunto significa que, se observarmos os cenários (Figura 4) originalmente elaborados em 2006 (ALA-FOSSI et al 2008, p. 20), a mídia radiofônica aparenta estar se desenvolvendo na direção de uma diversidade digital. Isso nos leva a pensar em pelo menos duas questões muito essenciais, sendo a primeira delas: qual a relevância real do papel da internet no futuro do rádio e da mídia de áudio? 


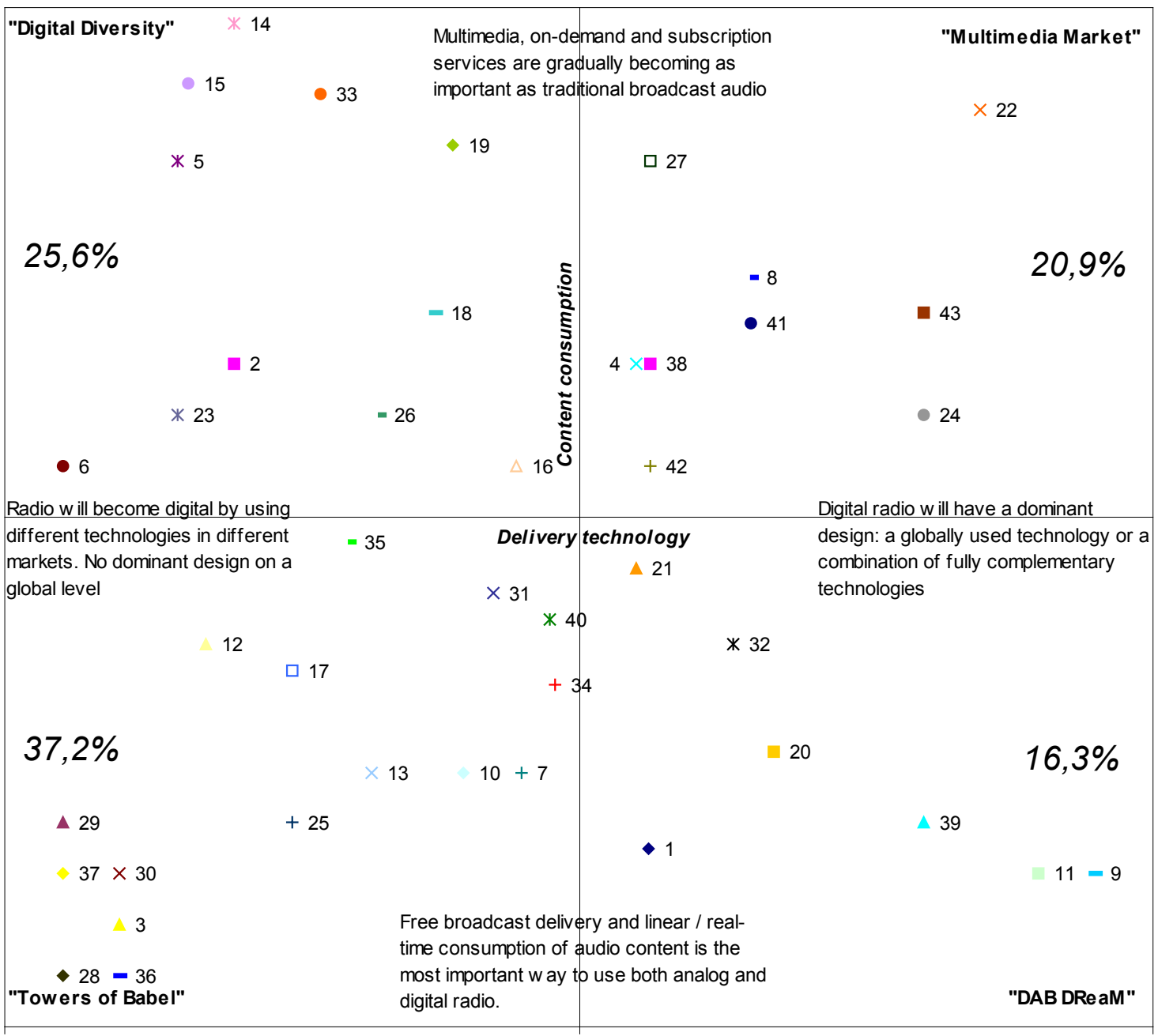

Figura 4: Quatro cenários futuros da mídia radiofônica. Fonte: ALAFOSSI et al, 2008, p. 20
$\mathrm{O}$ streaming pela internet pode fazer o rádio passar dos sistemas de transmissão de volta às redes de telecomunicações?

Já que o número de pessoas acessando todo tipo de conteúdo midiático pela internet só cresce o tempo todo, não há nenhuma dúvida de que o papel dela como forma de oferecer o rádio e a mídia sonora será muito maior e mais importante do que hoje. Alguns entusiastas da internet como Alexander Ljung, fundador da Soundcloud, estão mesmos convencidos de que, nela, "o som será mais importante que o vídeo” (ROSOFF, 2011). E, como já pudemos notar, os serviços que oferecem música online podem, até certo ponto, substituir de maneira bem-sucedida várias das funções sociais presentes no início do rádio musical. 
Ao mesmo tempo, a internet não será capaz de ocupar totalmente o lugar da transmissão radiofônica e do oferecimento do som. O motivo fundamental para isso é o mesmo pelo qual Telefon Hírmondó, um serviço sonoro instalado em Budapeste, Hungria, em 1893, migrou para a transmissão radiofônica em 1920: fatores econômicos e a relação custo-benefício. A tecnologia pode se desenvolver e se atualizar ao longo dos anos, mas as leis básicas da economia permanecem sempre as mesmas. A transmissão continua a ser simplesmente o melhor custo-benefício para alcançar grupos grandes de indivíduos ao mesmo tempo e em tempo real. Mas, caso você esteja tentando fazer algo diferente disso, a internet é uma opção que não deve ser negligenciada.

Nos Estados Unidos, cerca de mais de 14 mil estações de rádio devidamente licenciadas também fazem streaming pela internet, e a maioria delas transmite simultaneamente (simulcast) sua programação. Embora muitos (55\%) dos responsáveis técnicos por essas estações $(n=302)$ acreditem que já em 2015 o streaming deva atingir mais ouvintes do que o sinal transmitido, a maioria deles (77\%) acha que é prudente continuar transmitindo (ALETHEA, 2010, p. 11-12). Há evidências, ainda, de que a expectativa do público em relação ao streaming pela internet é, na verdade, diferente daquela em relação ao rádio: mais e mais americanos estão optando por faixas de stream feitas exclusivamente para a internet, só tocadas (pure play), com menos anúncios, em detrimento dos streamings feitos a partir das transmissões simultâneas da programação das estações de rádio (BRIDGE RATINGS, 2010). Os resultados de uma recente pesquisa de mercado alemã sugerem que o web radio e a transmissão radiofônica têm padrões de uso bem diferentes: a transmissão radiofônica tradicional tem um pico na parte da manhã, enquanto a rádio na web tem mais usuários na parte da tarde (GOLDHAMMER, 2010, p. 27). Então, talvez não seja uma boa ideia tentar simular uma transmissão regular de rádio na internet.

De qualquer forma, a internet tem hoje cerca de 2 bilhões de usuários, e espera-se que o volume de seu tráfego global chegue quase a explodir num futuro próximo. Tanto a Cisco quando a 
EMC estimam que o tráfego global da internet deve quadruplicar até 2015, ainda que não haja nenhum esforço sério de substituir a transmissão pela entrega através da internet (CISCO, 2012; EMC, 2010). De acordo com a revista Time, os centros de dados da internet são responsáveis atualmente por 1,3\% do consumo de eletricidade do mundo (NEWMAN, 2011), e o rápido crescimento da banda larga implica que um campo ainda maior do que se esperava originalmente do uso da transmissão será tomado (HUNTER, 2012). Num certo momento, a internet para de ser uma solução para tudo e se torna um problema: ela também tem limites. Teoricamente, uma capacidade extra de rede pode ser sempre construída e mais servidores podem ser comprados, mas, na prática, alguém tem de se interessar em investir mais em infraestrutura. Isso nos leva à segunda questão fundamental.

\section{O rádio digital tem uma chance real?}

Os maiores defensores do rádio digital nos dizem sempre que, como o rádio na internet nunca poderá substituir a transmissão radiofônica, precisamos também ter a transmissão física de rádio digital. Ele está na pauta dos comunicadores europeus desde a metade dos anos 80 e tem sido divulgado aos consumidores desde a metade dos anos 90 , mas com sucesso relativamente modesto (O’NEILL et al, 2010). A ideia original da Europa para uma transição de rádio digital em nível mundial transformou-se numa frustração global e numa fragmentação de mercado, com a disputa de muitos por padrões técnicos (RADIO WORLD, 2011). Talvez seja exemplar o fato de que o esforço de substituir o rádio analógico pelo digital mais sério até agora tem sido feito em países com forte tradição radiofônica, em que os indivíduos possuem bastantes aparelhos em uso (Figura 5). Em 2002, havia 2,6 bilhões de aparelhos de rádio sendo utilizados no mundo. Interessante notar que a maior proporção de rádios por pessoa era na Noruega, que atualmente tem sérias intenções de fechar sua estação FM de alcance nacional o mais rápido possível, sem frustrar seus ouvintes (WM, 2006; KUD, 2011). 


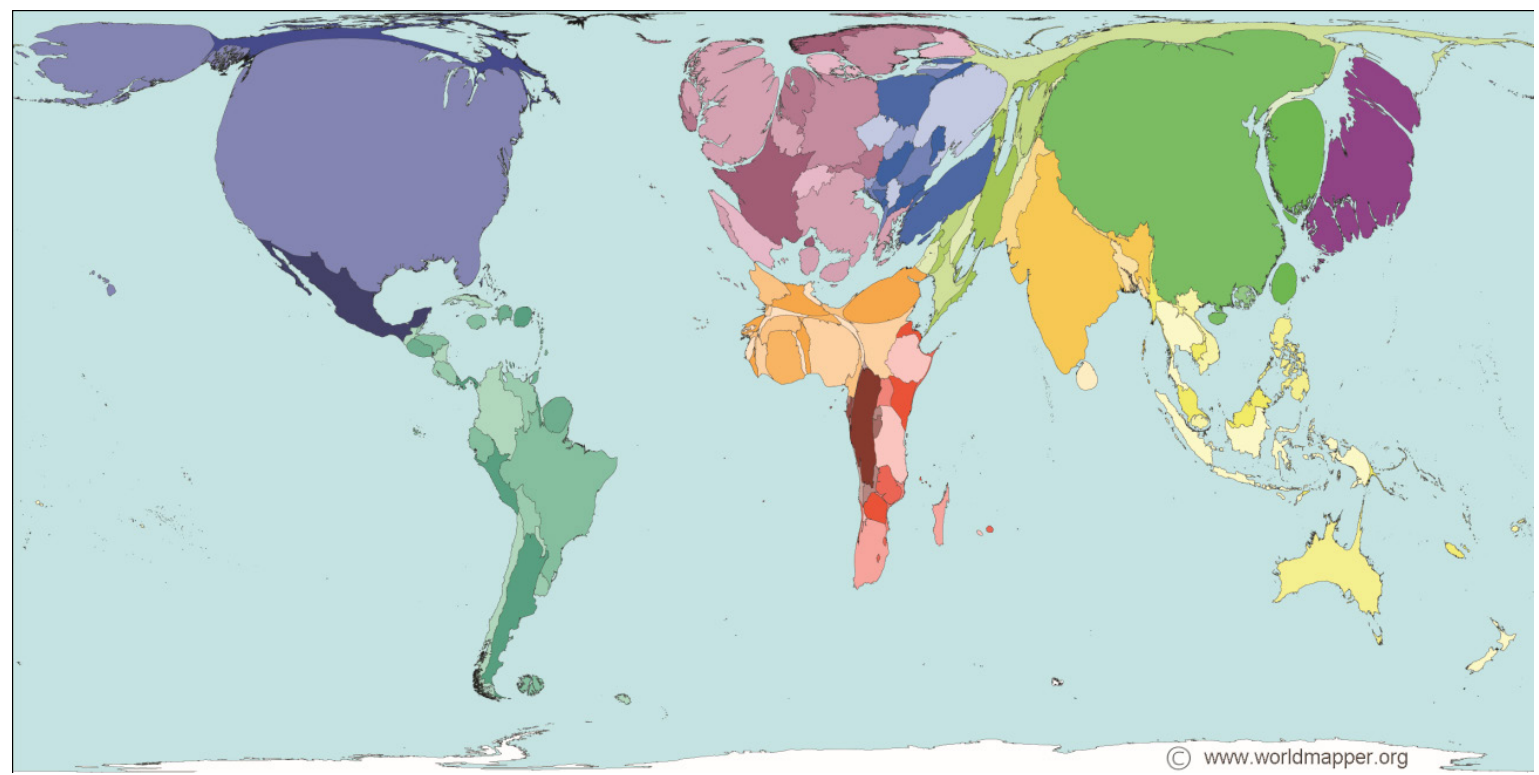

Figura 5: Aparelhos de rádio em uso no ano de 2002. Fonte:

Worldmapper. (C) Copyright Grupo Sasi (Universidade de Sheffield) e Mark Newman (Universidade de Michigan)
Contudo, os países que, no passado e no presente, mais investiram em rádio não são exatamente os mesmos dos quais mais se espera crescimento da economia nacional e na população. A Índia é um exemplo extremo - só um em cada três lares tinha rádio em 2008 (ITU, 2010, p. 158) —, mas estima-se que em 2050 o país será a terceira maior economia mundial, depois da China e dos Estados Unidos, tendo uma população de quase 1,5 bilhão de habitantes (WILSON; PURUSHOTHAMAN, 2003). No entanto, as coisas são muito diferentes na Europa. Não apenas pela atual recessão econômica, pelas dívidas públicas enormes e pela Eurocrise que já foi descrita como a pior crise econômica e política mundial desde a Segunda Grande Guerra (SPIEGEL, 2010). Somado a isso, a população de quase todos os membros da União Europeia está diminuindo numericamente e ficando cada vez mais velha. $\mathrm{O}$ pior quadro é esperado na Itália e na Espanha, em que a pirâmide populacional logo vai se parecer mais com urnas fúnebres do que com qualquer tipo de pirâmide. Mas também na Alemanha, o motor econômico da Europa, a população está envelhecendo e sendo reduzida (PARKKINEN, 2002, p. 6-9; SB, 2009). 
Uma parcela crescente do público ouvinte também deve usar a internet como plataforma de rádio ou de mídia sonora primária ou secundária. Ao mesmo tempo, especialmente na Índia e na China, mas também em muitos outros países asiáticos e africanos, a transmissão radiofônica está num estágio totalmente diferente de evolução e ainda tem um enorme potencial de crescimento, tanto em termos econômicos quanto em termos de cultura das comunicações. 


\section{Referências}

ALA-FOSSI, M. "For better pictures on radio: how Nokia's efforts for multimedia radio have shaped the radio landscape in Finland". In: HENDRICKS, J. A. (Ed.). The Palgrave handbook of global radio. Basingstoke; New York: Palgrave Macmillan, 2012a.

ALA-FOSSI, M. "Social obsolescence of the TV fee and the financial crisis of Finnish public service media". Journal of Media Business Studies, n. 9, n. 1, 2012b.

ALA-FOSSI, M.; HAARA, P. Toimiluvanvarainen radiotarjonta 2009. Yksityisten analogisten radiokanavien sisältötarjonta 20 suomalaiskaupungissa [Fornecimento de rádio dependente de licença - 2009. Fornecimento de conteúdo de rádio analógico privado em 20 cidades finlandesas]. Publicações do Ministério do Transporte e das Comunicações, 4/2010. Liikenne- ja viestintäministeriö, Helsinque, 2010.

ALA-FOSSI, M.; LAX, S.; O’NEILL, B.; JAUERT, P.; SHAW, H. "The future of radio is still digital - but which one? Expert perspectives and future scenarios for the radio media in 2015". Journal of Radio and Audio Media, v. 15, n. 1, 2008.

ALETHEA. Revenue generating radio technologies: market research report. New York: Alethea Research, nov. 2010. Disponível em: $<$ http://wheatstone-radio.com/Download-document/171-2.Revenue-Generating-Radio-Technologies.html>.

AMDI. Research summary report, African media development initiative. London: BBC World Service Trust, 2006. Disponível em: <http://downloads.bbc.co.uk/worldservice/trust/pdf/AMDI/ AMDI_summary_Report.pdf $>$.

BBC. Radio listening reaches new high. BBC News, 12 maio 2011(a). Disponível em: <http://www.bbc.co.uk/news/entertainmentarts-13374885>.

BBC. RAJAR 2011 Quarter 1: radio listening reaches record levels. 
Press release, 12 maio 2011(b). Disponível em <http://www.bbc. co.uk/pressoffice/pressreleases/stories/2011/05_may/12/rajar.shtml>.

BRIDGE RATINGS. Changing tide of internet radio. Press release, 14 set. 2010. Disponível em: <http://www.bridgeratings.com/ press.08.27.10.InternetRadioTrends.htm>.

CAREY, J. “The evolution of radio". In: NEUMANN, W. R. (Ed.). Media, technology and society: theories of media evolution. Ann Arbor: University of Michigan Press, 2010.

CISCO. Dawn of the zettabyte era: infographics. Cisco Systems, Inc. Publicado em: 23 jun. 2011. Disponível em: <http://blogs. cisco.com/news/the-dawn-of-the-zettabyte-era-infographic/>.

EBU. Public radio and new media platforms 2011: executive summary, 2011. Disponível em: <http://www.ebu.ch/CMSimages/ en/MONTAGE_WEB_Executive_summ_SIS_Radio_2011_A4_ tcm6-72187.pdf>.

EDISON RESEARCH. Radio's future ii: the 2010 American youth study. Market research report. Somerville, NJ: Edison Research, 2010. Disponível em: <http://www.edisonresearch.com/Edison_ Research_American_Youth_Study_Radios_Future.pdf > .

EDISON RESEARCH. The infinite dial 2011: navigating digital platforms. Market research report. Somerville, NJ: Edison Research, 2011. Disponível em: <http://www.edisonresearch.com/ home/archives/2011/04/the_infinite_dial_2011.php>.

EMC. The 2011 digital universe study: extracting value from chaos. EMC Corporation, 2011. Disponível em: <http://www.emc.com/ collateral/about/news/idc-emc-digital-universe-201 l-infographic.pdfs .

GOLDHAMMER, K. Radio Morgen und Übermorgen. Neue Verbreitungs- und Verwertungsmöglichkeiten [Rádio amanhã e depois de amanhã. Novas possibilidades para distribuição e receitas]. Apresentação em TKM-Tagung, Erfurt, 10 ago. 2010. Disponível em: http://www.radio2020.tlm.de/dokumente/100810_ VT_Goldhammer.pdf. 
HEINZE, U. "Radio and television consumption in Japan: a trilateral intercultural comparison with the UK and Germany". Electronic Journal of Contemporary Japanese Studies, artigo 3 em 2011. Publicado pela primeira vez em: 31 maio 2011. Disponível em: $<$ http://www.japanesestudies.org.uk/articles/2011/Heinze.html>.

HUNTER, P. "Europe defends terrestrial spectrum against mobile intrusion”. Broadcast Engineeering, 17 fev. 2012. Disponível em: $<$ http://broadcastengineering.com/news/europe-defends-spectrummobile/>.

ITU. World telecommunication/ICT development report 2010: monitoring the WSIS targets. A mid-term review, 2010. Disponível em: <http://www.itu.int/ITU-D/ict/publications/wtdr_10/index.html>.

KUD. Norwegian proposal on the digitization of radio: summary of report n. $8(2010-2011)$ to the storting. Oslo: Ministério da Cultura norueguês. Publicado em: 4 fev. 2011. Disponível em: $<$ http://www.regjeringen.no/upload/KUD/Medier/Rapporter/V0951E-SummaryReportNo8_2010-11.pdf>.

NEWMAN, J. "6 things you'd never guess about Google’s energy use”. Time Magazine, 9 set. 2011. Disponível em: <http://techland. time.com/201 1/09/09/6-things-youd-never-guess-about-googlesenergy-use/\#ixzz2LjXJSNtX>.

NHK. 50 years of Japanese broadcasting. Tokyo: Nippon Hoso Kyokai, Radio \& TV Culture Research Institute, 1977.

MYERS, M. Radio and development in Africa: a concept paper prepared for the International Development Research Centre (IDRC) of Canada. Ago. 2008 (revisado em mar. 2009). Disponível em: <http://www.idrc.ca/uploads/user-S/12581214041Radio_and_ Development_in_Africa,_concept_paper.pdf $>$.

OFCOM. The communications market 2011, 3: radio and audio. London: Ofcom, 2011. Disponível em: <http://stakeholders.ofcom. org.uk/binaries/research/cmr/cmrl1/UK_Doc_Section_3.pdf>.

OFCOM. The international communications market 2008, 6: radio. London: Ofcom, 2008. Disponível em: <http://stakeholders.ofcom. org.uk/binaries/research/cmr/radio7.pdf $>$. 
O’NEILL, B; ALA-FOSSI, M; JAUERT, P; LAX, S; NYRE, L.; SHAW, H. (Eds.). Digital radio in Europe: technologies, industries and cultures. Bristol: Intellect, 2010.

PARKKINEN, P. Suomen ja muiden unionimaiden väestön ikärakenne vuoteen 2050 [A estrutura da população da Finlândia e outros países membros da UE em 2050]. VATT- discussion initiatives 265. Helsinque: VATT, Instituto governamental de pesquisa econômica, 2002. Disponível em: <http://www.vatt.fi/file/ vatt_publication_pdf/k265.pdf>.

RAB. Multi-platform radio: why new digital platforms will mean more listening and increased interactivity. London: Radio Advertising Bureau, 2009a. Disponível em: <http://www.rab.co.uk/ publicationDocs/DigitalPublicationQ4.pdf $>$.

RAB. Radio and the digital native: how 15-24s are using radio and what this tells us about the future of the medium. London: Radio Advertising Bureau, 2009b. Disponível em: <http://www.rab. co.uk/publicationDocs/DigitalNativePDF.pdf>.

ROSOFF, M. "Four reasons why sound will be bigger than video online”. Business Insider, 19 dez. 2011. Disponível em: <http:// articles.businessinsider.com/2011-12-19/tech/30533264_1_ smartphone-video-scary-movie $>$.

RW. "Countries using digital radio technologies". Radio World. Publicado em: 21 jul. 2011. Disponível em:<http://www.radioworld. com/article/countries-using-digital-radio-technologies/23967>.

SB. 12th coordinated population projection. Wiesbaden: Statistisches Bundesamt, 2009. Disponível em: <https://www. destatis.de/bevoelkerungspyramide/>.

SPIEGEL. "European Central Bank president Jean-Claude Trichet: a 'quantum leap' in governance of the Euro Zone is needed". Spiegel Online International, 15 maio 2010. Disponível em: <http://www. spiegel.de/international/europe/european-central-bank-presidentjean-claude-trichet-a-quantum-leap-in-governance-of-the-eurozone-is-needed-a-694960.html>. 
SR. Framtidsutredningen [Análises futuras]. Estocolmo: Sveriges Radio, 2010a. Disponível em: <http://sverigesradio.se/diverse/ appdata/isidor/files/3113/9379.pdf>

SR. Mediekonsumtion i framtiden [O consumo de mídia no futuro]. Estocolmo: Sveriges Radio. Publicado em: 26 out. 2010(b). Disponível em: <http://sverigesradio.se/sida/gruppsida.aspx?progra mid $=3113 \&$ grupp $=11144 \&$ artikel $=4131310 \&$ sida $=2>$.

WILSON, D.; PURUSHOTHAMAN, R. "Dreaming with BRICs: the path to 2050". Global Economics Paper, n. 99, New York, 2003. Disponível em: <http://www.goldmansachs.com/our-thinking/ topics/brics/brics-reports-pdfs/brics-dream.pdfs.

WM. Radios in use: a world map by Sasi Group (University of Sheffield) and Mark Newman (University of Michigan), 2006. Disponível em: <http://www.worldmapper.org/posters/ worldmapper_map340_ver5.pdf>.

YOSHIDA, R.; NAKANO, S. Changes and trends in media use: from the results of the 2005 Japanese time use survey. NHK Broadcasting Studies 2006-2007, n. 5, 2007. Disponível em: <http:// www.nhk.or.jp/bunken/english/pdf/070601-05.pdf>.

*O texto foi fornecido pelo autor em inglês e traduzido por Andrea Limberto. 